\title{
Hall-Petch strengthening in Fe-34.5Mn-0.04C steel cold-rolled, partially recrystallized
} and fully recrystallized

Wang, Y.H.; Kang, J. M.; Peng, Y.; Wang, T. S.; Hansen, N.; Huang, X.

Published in:

Scripta Materialia

Link to article, DOI:

10.1016/j.scriptamat.2018.06.019

Publication date:

2018

Document Version

Peer reviewed version

Link back to DTU Orbit

Citation (APA):

Wang, Y. H., Kang, J. M., Peng, Y., Wang, T. S., Hansen, N., \& Huang, X. (2018). Hall-Petch strengthening in Fe-34.5Mn-0.04C steel cold-rolled, partially recrystallized and fully recrystallized. Scripta Materialia, 155, 41-45. https://doi.org/10.1016/j.scriptamat.2018.06.019

\section{General rights}

Copyright and moral rights for the publications made accessible in the public portal are retained by the authors and/or other copyright owners and it is a condition of accessing publications that users recognise and abide by the legal requirements associated with these rights.

- Users may download and print one copy of any publication from the public portal for the purpose of private study or research.

- You may not further distribute the material or use it for any profit-making activity or commercial gain

- You may freely distribute the URL identifying the publication in the public portal 


\title{
Hall-Petch Strengthening in Fe-34.5Mn-0.04C steel cold-rolled, partially recrystallized and fully recrystallized
}

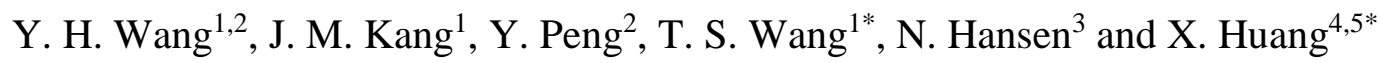 \\ ${ }^{1}$ State Key Laboratory of Metastable Materials Science and Technology, Yanshan University, \\ Qinhuangdao 066004, China \\ ${ }^{2}$ National Engineering Research Center for Equipment and Technology of Cold Strip Rolling, \\ Yanshan University, Qinhuangdao 066004, China \\ ${ }^{3}$ Ris $\varnothing$ Campus, Technical University of Denmark, DK-4000 Roskilde, Denmark \\ ${ }^{4}$ College of Materials Science and Engineering, Chongqing University, Chongqing 400045, China \\ ${ }^{5}$ Department of Mechanical Engineering, Technical University of Denmark, DK-2800 Kgs. Lyngby, \\ Denmark
}

* Corresponding author: Email: tswang@ysu.edu.cn; xihu@mek.dtu.dk

An Fe-34.5Mn-0.04C steel has been processed by cold rolling and annealing to prepare samples with a lamellar structure, a recrystallized grain structure and a composite structure of layers of recovered and recrystallized structures. For the recrystallized grain structure and the lamellar structure, the flow stress has been analyzed by applying Hall-Petch formulations. For the composite structure, the rule of mixture has been applied to calculate the flow stress, revealing an extra strengthening from a constraint effect. An excellent combination of strength and ductility has been found in a composite with $10 \%$ hard lamellae in a recrystallized grain structure.

Keywords: Hall-Petch effect; rolling; annealing; laminated composite structure; steel

A combination of high strength and ductility is important in the design and processing of metals and alloys for engineering applications [1-3]. Successful results have been obtained by combining in a structure of hard and soft volume elements contributing respectively to the strength and ductility of the material. Examples are a bimodal distribution of grain sizes in $\mathrm{Cu}$ [4] and a heterogeneous lamella 
structure in $\mathrm{Ti}[5]$. In both examples the processing route is rolling and annealing and the structure is subdivided by boundaries of low, medium and high angle. In a recent study [6], a laminated structure composed of hard layers of recovered lamellar structures and soft layers of recrystallized equiaxed grains was produced in a single phase austenitic steel Fe-34.5Mn- $0.04 \mathrm{C}$ by cold-rolling and annealing. Enhanced yield stress was obtained in the composite structure while maintaining tensile ductility as good as the fully recrystallized grain structure.

Table 1. Microstructure and structural parameters determined for eight samples of Fe-34.5Mn-0.04C steel cold rolled to $90 \%$ followed by annealing at different conditions.

\begin{tabular}{|c|c|c|c|}
\hline Sample & $\begin{array}{l}\text { Cold rolling and } \\
\text { Annealing }\end{array}$ & Microstructure & $\begin{array}{c}\text { Boundary spacing }\left(d_{G N B}\right) / \\
\text { Grain size }\left(d_{g}\right),(\mu \mathrm{m})\end{array}$ \\
\hline 1 & cold-rolled to $90 \%$ & Lamellar structure & 0.047 ( Boundary spacing ) \\
\hline 2 & $500{ }^{\circ} \mathrm{C}, 1$ hour & Lamellar structure & 0.067 ( Boundary spacing ) \\
\hline 3 & $550^{\circ} \mathrm{C}, 1$ hour & $\begin{array}{l}\text { Composite structure: } \\
\text { Lamellar (77\%) } \\
\text { Equiaxed grains (23\%) }\end{array}$ & $\begin{array}{c}0.083 \text { (Boundary spacing ) } \\
1.40 \text { (Grain size })\end{array}$ \\
\hline 4 & $600^{\circ} \mathrm{C}, 1$ hour & $\begin{array}{l}\text { Composite structure: } \\
\text { Lamellar (10\%) } \\
\text { Equiaxed grains }(90 \%)\end{array}$ & $\begin{array}{c}0.14 \text { ( Boundary spacing ) } \\
2.2(\text { Grain size })\end{array}$ \\
\hline 5 & $700^{\circ} \mathrm{C}, 1$ hour & Equiaxed grains & 2.3 \\
\hline 6 & $800{ }^{\circ} \mathrm{C}, 1$ hour & Equiaxed grains & 3.8 \\
\hline 7 & $900{ }^{\circ} \mathrm{C}, 1$ hour & Equiaxed grains & 10.8 \\
\hline 8 & $1000^{\circ} \mathrm{C}, 1$ hour & Equiaxed grains & 21.0 \\
\hline
\end{tabular}

This study aims at further exploring the strengthening mechanisms in that laminated composite based on the rule of mixture that normally is applied in the analysis of the strength of composites. In doing so, it is suggested to establish Hall-Petch relationships for the lamellar structure and the recrystallized equiaxed grain structure. For testing a series of samples with three different types of microstructure were prepared by cold rolling and annealing: (1) lamellar structures of different lamellar boundary 
spacings, (2) recrystallized equiaxed grain structures of different grain sizes, and (3) composite structures. An ingot was produced using a vacuum induction furnace, and then forged in the temperature range of $800-1100^{\circ} \mathrm{C}$ to form a $13 \mathrm{~mm}$ thick plate [6]. The plate was cold-rolled to $90 \%$ in thickness reduction. Annealing treatments under different conditions (see Table 1) were carried out to obtain the three types of microstructure desired. In total, eight samples were prepared, as listed in Table 1, for microstructural characterization and tensile testing. The microstructure was characterized by transmission electron microscopy (TEM) with a JEM-2100 electron microscope operated at $200 \mathrm{kV}$, and by scanning electron microscopy (SEM) and electron backscatter diffraction (EBSD) with a Hitachi S-3400N-II scanning electron microscope. The step size for the EBSD scanning was $100 \mathrm{~nm}$. All the microstructural observations were conducted on the longitudinal section containing the rolling direction (RD) and the normal direction (ND). Tensile specimens with gage dimensions of $10 \mathrm{~mm}$ long and $5 \mathrm{~mm}$ wide were prepared such that the tensile direction was parallel to the RD. Tensile tests were conducted at ambient temperature with an initial strain rate of $10^{-3} \mathrm{~s}^{-1}$. An extensometer was attached on the specimen during the tensile test for a precise measurement of the tensile strain.

Figs. 1-3 show the microstructure in the cold-rolled state and after annealing under several selected conditions illustrating the lamellar structure, laminated composite structure and recrystallized equiaxed grain structure. The composite structure is characterized by layers of recovered lamellar structures and layers of recrystallized fine grains. The formation of this composite structure may have its cause in a structural subdivision during cold rolling into lamellae separating different texture components. The layers may have different stored energies and therefore recover and recrystallize with different rates [7] forming the composite structure. A summary of the identification of three types 
of microstructure and the quantification of the lamellar boundary spacing $\left(d_{G N B}\right)$ for the lamellar structure (samples 1 and 2) and the grain size $\left(d_{g}\right)$ for the recrystallized grain structure (samples 5-8) is shown in Table 1. The boundary spacing is the distance between lamellar boundaries measured perpendicular to the rolling plane. For the composite structure (sample 3 and 4), the lamellar boundary spacing, the grain size, and the volume fractions of the lamellar structure and recrystallized grains were determined separately. The structural parameters have been determined as average values with an acceptable standard deviation based on examination of relatively large areas. It is realized that an average value is an approximation as both the deformed and recovered structures show heterogeneity for example S-bands or microshear bands (see Fig. 3a). However as the structural parameters find their application in strength-structure relationship which also are approximations, the effect of local heterogeneity may not be significant.
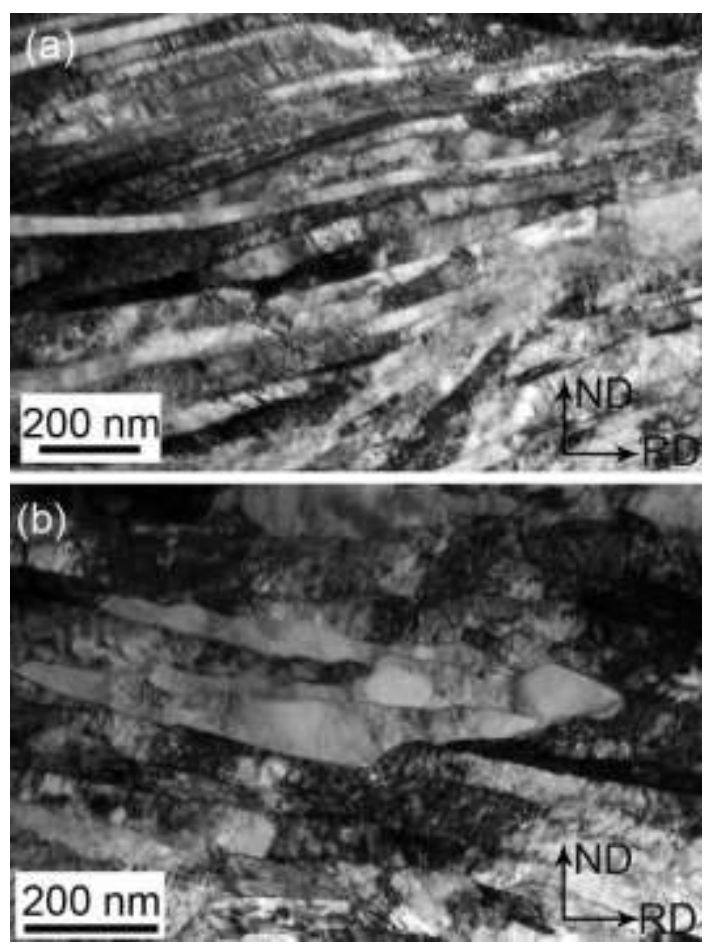

Fig. 1. TEM images of the Fe-34.5Mn-0.04C steel showing the lamellar structure. (a) Cold-rolled to $90 \%$ and (b) subsequently annealed at $500{ }^{\circ} \mathrm{C}$ for 1 hour. 


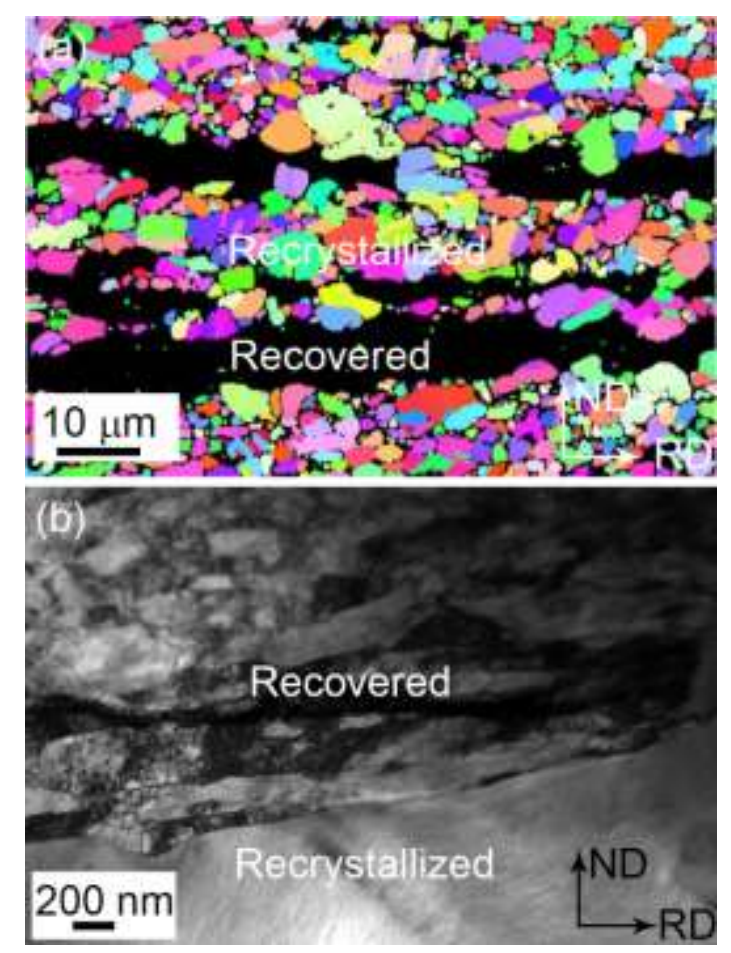

Fig. 2. (a) EBSD map and (b) TEM image showing the laminated composite structure of the Fe$34.5 \mathrm{Mn}-0.04 \mathrm{C}$ steel cold-rolled to $90 \%$ and subsequently annealed for 1 hour at $600^{\circ} \mathrm{C}$.

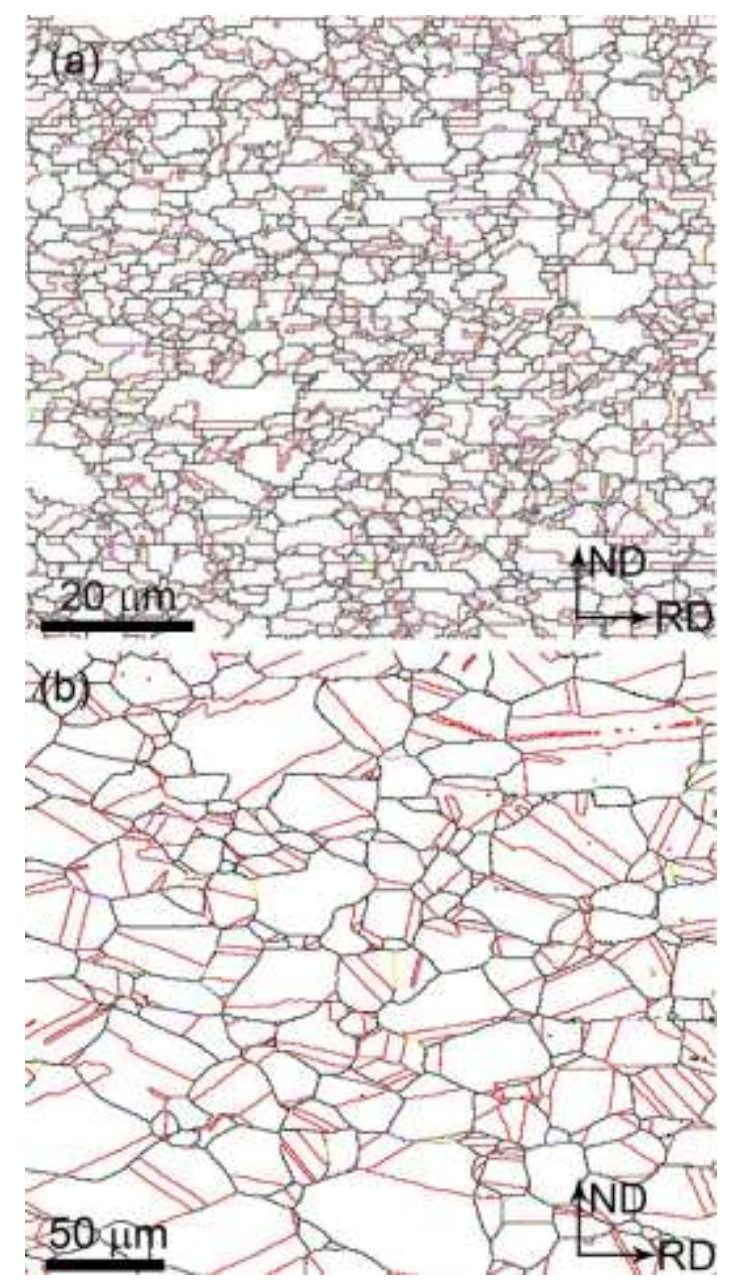


Fig. 3. EBSD maps of the Fe-34.5Mn-0.04C steel cold-rolled to $90 \%$ and subsequently annealed for 1 hour at (a) $700{ }^{\circ} \mathrm{C}$ (b) $900{ }^{\circ} \mathrm{C}$.
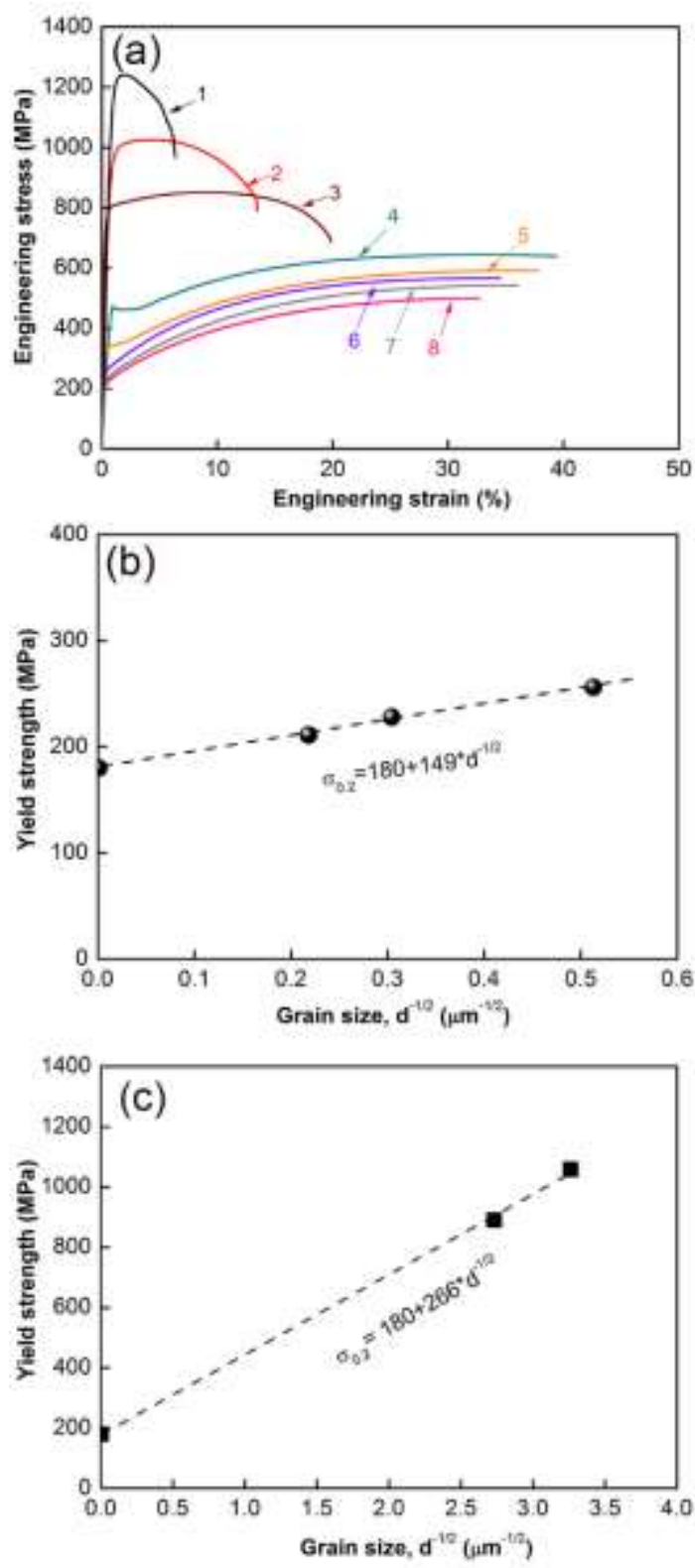

Fig. 4 (a) Tensile stress-strain curves of the Fe-34.5Mn- $0.04 \mathrm{C}$ steel treated under 10 different conditions (see Table 1 for sample specifications). (b) Hall-Petch plot for fully recrystallized samples 6, 7 and 8, giving a value of $\sigma_{0}=180 \mathrm{MPa}$. (c) Hall-Petch plot for samples 1 and 2 with lamellar structure by taking the same value of $\sigma_{0}=180 \mathrm{MPa}$ and $\mathrm{d}=2 \mathrm{~d}_{\mathrm{GNB}}$.

Figure 4a shows the tensile stress-strain curves for the eight samples tested. It is seen that a continuous 
flow occurs in samples 1 and 2 with the lamellar structure and in samples 6,7 and 8 with relatively large grain sizes of 3.8, 10.8 and $21.0 \mu \mathrm{m}$. However, a discontinuous flow associated with a small Lüders elongation takes place in sample 4 (composite structure) and sample 5 (with a fine grain size of $2.3 \mu \mathrm{m}$ ). Note that the two samples with composite structures show a remarkable combination of strength and ductility (curves 3 and 4 in Fig. $4 a$ ): sample 3 with 77\% recovered lamellar structures (boundary spacing $83 \mathrm{~nm}$ ) and 23\% recrystallized grains (grain size $1.4 \mu \mathrm{m}$ ) has a flow stress $(0.2 \%$ offset) of $783 \mathrm{MPa}$ and tensile elongation of $19.9 \%$; and sample 4 with $10 \%$ lamellar structures (lamellar boundary spacing $140 \mathrm{~nm}$ ) and 90\% recrystallized grains (grain size $2.2 \mu \mathrm{m}$ ) exhibits a higher strength than the fully recrystallized samples with different grain sizes (samples 5-8) while maintaining a high tensile elongation.

To analyze the strength of the composite structure composed of recrystallized grains and lamellar structures (samples 3 and 4), the Hall-Petch relationship is first established for the fully recrystallized grain structure and the lamellar structure. The Hall-Petch relationship has over the years been given different formulations based on a general relationship:

$$
\sigma=\sigma_{0}+\sigma(\rho)+k_{1} \frac{1}{\sqrt{d_{g}}}
$$

where $\sigma$ is the flow stress. $\sigma_{0}$ is the friction stress for a matrix with no defects such as particles and precipitates but only containing dislocations with a strength contribution $\sigma(\rho) . d_{g}$ is the grain size of a polycrystalline metal. In the deformed and recovered state the volume between the original grain boundaries and the deformation induced boundaries contain random dislocations and dislocation boundaries. For this type of structure the flow stress can be expressed as: 


$$
\sigma_{f}=\sigma_{0}+\sigma(\rho)+\sigma(b)
$$

where $\sigma(\rho)$ is the strength contribution from dislocations proportional to the square root of the dislocation density. $\sigma(b)$ is the contribution from medium and high angle lamellar boundaries which resist dislocation glide. $\sigma(b)$ is proportional to the inverse square root of the average distance between lamellar boundaries, termed $d_{G N B}$ (see Table 1) referring to the boundaries being geometrically necessary boundaries [8] . Based on a recent observation [9] of a linear relationship between $1 / d_{G N B}$ and the dislocation density between the GNBs, one can reduce Eq. 2 to a oneparameter equation:

$\sigma=\sigma_{0}+k_{2} \frac{1}{\sqrt{d_{G N B}}}$

For the lamellar structure in deformed and recovered samples, $d_{G N B}$ is determined as the average distance between lamellar boundaries measured perpendicular to the rolling plane. The average slip distance when loading in the rolling direction is taken as $2 d_{G N B}[10]$ and Eq. 2 can be written as $\sigma=\sigma_{0}+k_{2} \frac{1}{\sqrt{2 d_{G N B}}}$

For a laminated composite structure composed of hard layers of recovered lamellae together with soft layers of recrystallized grains, the flow stress can be expressed by the rule of mixture:

$$
\sigma_{f}=\sigma_{0}+k_{1} \frac{1}{\sqrt{d_{g}}}(1-f)+k_{2} \frac{1}{\sqrt{2 d_{G N B}}} f
$$


where $\mathrm{f}$ is the fraction of recrystallized structure with a grain size of $d_{g}$.

In the analysis of the Hall-Petch equations, an important parameter is $\sigma_{0}$ which cannot be determined directly. Based on the results obtained from the three recrystallized samples with grain sizes in the range $3.8-21.0 \mu \mathrm{m}$ (samples 6, 7 and 8), which show continuous flow, a Hall-Petch analysis gives $\sigma_{0}=180 \mathrm{MPa}$ and $k_{1}=149 \mathrm{MPa}^{0.5} \mathrm{~m}^{0.5}$ (see Fig. $4 \mathrm{~b}$ ). Note that the data from the recrystallized sample 5 was not used for this analysis as a discontinuous flow occurred in this sample, indicating an additional contribution from the source hardening to the strength, which is to be discussed later. Based on $\sigma_{0}$ and the flow stress $(0.2 \%)$ of the deformed sample and lightly recovered sample, $k_{2}$ has been determined to be about $266 \mathrm{MPa \mu m}^{0.5}$ for the lamellar structure (see Fig. 4c).

Based on the Hall-Petch relationships established for the recrystallized grain structure and the lamellar structure, the flow stress in the two samples with composite structures was calculated applying the rule of mixture. The calculated results are shown in Table 2. It is seen that the calculated flow stress is significantly smaller than the experimentally measured flow stress. It should be pointed out that this mismatch stress shows a large difference between the two samples. To analyze the cause(s) of this difference will require a more detailed structural analysis as it may be realized that the samples show large differences in the structural parameters. The mismatch stress in Table2 is therefore important as it indicate that such a stress must be taken into account as a strengthening mechanism and that this mismatch stress in significant. This mismatch stress may have different causes:

(i) The flow stress in the hard layers of lamellar structures is about 3-4 times larger than the flow stress of the soft layers of recrystallized grains for both sample 3 and 4 . During tensile straining to a given stress the plastic deformation will be heterogeneously distributed with 
a larger plastic strain in the soft layers than in the hard layers. An accommodation of this strain can give rise to slip on supplementary slip systems which may strain harden the soft lamellae (constraint effect) by the formation of geometrically necessary dislocations $[5,11]$.

(ii) The flow of sample 4 is discontinuous associated with a small yield drop. Such a yield drop, which characterizes the flow of many fine grained metals such as $\mathrm{Al}[12,13,14]$, IF steel [12,15], high manganese steels [16] and Ti [5], may have its cause in the lack of mobile dislocations requiring a supplementary stress to activate dislocation sources $[17,18]$. Note that similar source hardening also occurred in the recrystallized sample 5 for which the contribution of the source hardening can be estimated from the difference between measured flow stress and the calculated flow stress based on the Hall-Petch relationship established for the recrystallized samples (Fig. 3b). The calculated result for sample 5 is also shown in Table 2, resulting in an estimate of source hardening of $48 \mathrm{MPa}$. As the grain size of the recrystallized grains in sample $4(2.2 \mu \mathrm{m}$, see Table 1$)$ is comparable to that of sample $5(2.3 \mu \mathrm{m})$, the source hardening due to the fine grain size in sample 4 may be of similar order of magnitude to that observed in sample 5. Subtracting this source hardening contribution from the total difference for sample 4 (140 MPa, see Table 2), the strength contribution from the constraint effect is about $90 \mathrm{MPa}$.

The above analysis suggests that the constraint effect can have a strength contribution of about $10-20 \%$ in the two samples of composite structure that have been studied. For engineering applications the optimization of strength and ductility of such composites will be investigated by testing of key parameters such as the volume fraction and the distribution of the hard and soft lamellae in the steel. 
Table 2. The measured and calculated yield stresses, and their differences for samples 3 and 4 of composite structures and sample 5 of a fine grain structure $(2.3 \mu \mathrm{m})$ showing a discontinuous flow.

\begin{tabular}{cccc}
\hline Sample & $\begin{array}{c}\text { Measured yield stress } \\
(\mathrm{MPa})\end{array}$ & $\begin{array}{c}\text { Calculated yield stress } \\
(\mathrm{MPa})\end{array}$ & $\begin{array}{c}\text { Difference } \\
(\mathrm{MPa})\end{array}$ \\
\hline 3 & 783 & 712 & 71 \\
4 & 461 & 321 & 140 \\
5 & 326 & 278 & 48 \\
\hline
\end{tabular}

In summary, a series of samples with lamellar structures, recrystallized equiaxed grain structure, and laminated composite structures have been prepared and tested, and an excellent combination of high strength and good ductility has been obtained in a composite sample with $10 \%$ hard lamellae in a recrystallized grain structure. Based on Hall-Petch relationships for the lamellar structure and the recrystallized grain structure, the rule of mixture is applied to calculate the flow stress of the composite samples, which reveals an important contribution from a constraint effect. The present study confirms previous research of the positive effect on the mechanical behavior when a structure is subdivided by into hard and soft regions. The newness is that a laminated composite with high strength and ductility has been produced in a single phase alloy by conventional rolling and annealing.

The authors gratefully acknowledge the support from the National Natural Foundation of Hebei Province, China (Grant No. E2018203312). XH thanks the support of State Key Research and Development Program of MOST of China (2016YFB0700401). NH thanks the support of the 111 Project (B16007) by the Ministry of Education and the State Administration of Foreign Experts Affairs of China.

\section{References}

[1] Y. T. Zhu, X. Z. Liao, Nature Mater. 3 (2004) 351-352. 
[2] M. A. Meyers, A. Mishra, D. J. Benson, Prog. Mater. Sci. 51 (2006) 427-556.

[3] L. Lu, Y. F. Shen, X. H. Chen, L. H. Qian, K. Lu, Science 304 (2004) 422-426.

[4] Y. M. Wang, M.W. Chen, F. H. Zhou, E. Ma, Nature 419 (2002) 912 - 915.

[5] X. L. Wu, M. X. Yang, F. P. Yuan, G. L. Wu, Y. Wei, X. X. Huang, Y. T. Zhu, Proc. Natl. Acad. Sci. U.S.A. 112 (2015) 14501 - 14505.

[6] Y. H. Wang, J. M. Kang, Y. Peng, T. S. Wang, N. Hansen and X. Huang, J. Mater. Sci. Techn. In print.

[7] Q. Xing, X. X. Huang, N. Hansen, Mater. Trans. A 37A (2006) 1311-1322.

[8] D. Kuhimann-Wilsdorf, N. Hansen, Scripta Metall. Mater. 25 (1991) 1557-1562.

[9] D. A. Hughes, N. Hansen, Acta Mater. 148 (2018) 374-383.

[10] D. A. Hughes, N. Hansen, Acta Mater. 48 (2000) 2985-3004

[11] M. F. Ashby, Philos. Mag. 21 (1970) 399-411.

[12] N. Tsuji, Y. Ito, Y. Saito, Y. Minamino, Scripta Mater,47 (2002) 893-899.

[13] C. Y. Yu, P. W. Kao, C. P. Chang, Acta Mater. 53 (2005) 4019-4028.

[14] N. Kamikawa, X. Huang, N. Tsuji, N. Hansen, Acta Mater. 570 (2009) 4198-4208.

[15] S. Gao, M. C. Chen, M. Joshi, A. Shibata, N. Tsuji. J. Mater. Sci. 49 (2014) 6536-6542.

[16] R. Ueji, N. Tsuchida, D. Terada, N. Tsuji, Y. Tanaka, A. Takemura, K. Kunishige, Scripta Mater 59 (2008) 963-66

[17] X. Huang. Scripta Mater. 60 (2009) 1078-1082.

[18] N. Hansen. Proceedings of the $35^{\text {th }}$ Risø International Symposium on Materials Science. 2014 (Roskilde), pp.293-303. 